\title{
Two Cases of Endogenous Endophthalmitis Caused by Gram-Positive Bacteria with Good Visual Outcome
}

\author{
Machiko Itoh ${ }^{\mathrm{a}, \mathrm{b}}$ Junko Ikewaki ${ }^{\mathrm{a}}$ Kenichi Kimoto ${ }^{\mathrm{a}}$ \\ Yuji Itoh ${ }^{a, b}$ Kei Shinoda ${ }^{a, c}$ Kazuo Nakatsuka ${ }^{a}$ \\ aDepartment of Ophthalmology, Oita University Faculty of Medicine, Oita, \\ ${ }^{b}$ Department of Ophthalmology, Kyorin Eye Center, and 'Department of \\ Ophthalmology, Teikyo University School of Medicine, Tokyo, Japan
}

\section{Key Words}

Endogenous endophthalmitis · Electroretinogram · Vitrectomy · Gram-positive coccus

\begin{abstract}
Background: Endogenous endophthalmitis is a rare disease and its visual prognosis is poor.

Case Reports: We present two patients, a 60-year-old man and a 53-year-old man, who developed endogenous endophthalmitis caused by Gram-positive organisms but recovered good vision after antibiotics and vitrectomy.

Results: The first patient complained of ocular pain and visual decrease in his right eye. Ophthalmoscopy showed inflammation in the anterior chamber and vitreous opacities. Antibiotic was administrated systemically, and blood culture detected Streptococcus anginosus. He underwent successful heart surgery for endocarditis and total dental extraction for severe gingivitis. Vitrectomy was performed 36 days after the onset and vision improved from 0.02 to 0.7 . The second patient was referred for acute visual decrease in his left eye. Severe iritis and vitreous opacities were observed, and systemic examination showed acute pyelitis and prostatic abscesses. Blood cultures detected Staphylococcus sp., and systemic antibiotics were given. Vitrectomy was performed 12 days after the onset, and vision improved from 0.06 to 1.2 .

Conclusions: We conclude that the rapid treatment with systemic antibiotics for the organisms at the primary site, and the vitrectomy, even though delayed, can lead to a good recovery of vision.
\end{abstract}




\section{Introduction}

Endogenous endophthalmitis is a chorioretinal infection caused by organisms which pass into the eye through the blood stream from a distant organ $[1,2]$. This route of infection accounts for $30 \%$ of the cases of infectious endophthalmitis, and there has been an increase in the incidence because of the increased number of older patients with sepsis [3]. Systemic and topical antibiotics and vitrectomy are effective, but in general, the visual outcome is poor, and the infection even leads to blindness in some cases [4-9]. The poor outcome is thought to be due to a delay in the diagnosis, virulence of the microorganisms, delay in eye surgery because of a poor systemic condition, and poor wound healing after surgery $[4,5,10]$.

We treated two patients with endogenous endophthalmitis caused by Gram-positive cocci who recovered good vision in spite of delayed surgery due to poor systemic conditions.

\section{Case Reports}

\section{Case 1}

A 60-year-old man noticed that his right eye was inflamed and that he had blurred vision on August 18,2008 . He visited our clinic with complaints of ocular pain and decreased vision OD on September 1, 2008. He had lost $24 \mathrm{~kg}$ of body weight during the previous 2 months. On examination, his bestcorrected visual acuity (BCVA) was $0.02 \mathrm{OD}$ and $0.6 \mathrm{OS}$. Intraocular pressure was $20 \mathrm{~mm} \mathrm{Hg} \mathrm{OD}$ and $10 \mathrm{~mm} \mathrm{Hg}$ OS. Slit-lamp examination revealed severe iritis with fibrin precipitates OD and no particular findings OS. Ophthalmoscopy showed dense vitreous opacity preventing the fundus view OD, and a white mass on the fovea OS. Optical coherence tomography (OCT) showed that the white mass OS was contiguous with the outer retinal layer (fig. 1). Ultrasound echography (US) showed no retinal detachment and the single-flash electroretinogram (ERG) was almost flat OD (fig. 1). Blood tests showed a white blood cell (WBC) count of $12,000 / \mu l$ composed of $90 \%$ neutrophils. C-reactive protein (CRP) was $4.5 \mathrm{mg} / \mathrm{dl}$. Systemic examination showed approximately $3 \mathrm{~mm}$ of brain abscess in the left occipital lobe and infectious endocarditis.

Two g/day of imipenem was given intravenously. A thorough discussion with the internist led to the conclusion that the endocarditis and other inflammation should be treated first. The patient underwent mitral valve replacement surgery, and 3 days later, the foveal white mass disappeared and BCVA improved to 1.0 OS. Blood cultures grew Streptococcus anginosus, which was thought to be the cause of the endophthalmitis. The patient was then found to have severe gingivitis and total dental extraction was performed on September 11, 2008. Pars plana vitrectomy (PPL) combined with phacoemulsification (PEA) and intraocular lens (IOL) implantation was performed on September 23. The subretinal abscess and the retina above the inferonasal region were excised, and photocoagulation was performed.

No bacteria were found in the vitreous sample. Three weeks after the vitrectomy, the BCVA OD improved to 0.7 , and the patient has kept this vision for 10 months.

\section{Case 2}

A 53-year-old diabetic patient was referred on January 19, 2008 because of an acute decrease in the vision OS. His BCVA was $1.2 \mathrm{OD}$ and $0.06 \mathrm{OS}$, and the intraocular pressure was $18 \mathrm{~mm} \mathrm{Hg}$ OU. Slitlamp examination revealed no particular abnormalities OD and ciliary injection and hypopyon OS. Ophthalmoscopy showed diabetic retinopathy OD, and a dense vitreous opacity and a white mass in the nasal retinal region OS. US showed no retinal detachment, and single-flash ERG showed highly reduced a-wave OS (ig. 2). Blood tests showed a WBC count of 12,800/ $\mu$ l composed of $85 \%$ neutrophils, 9.5 $\mathrm{mg} / \mathrm{dl}$ of CRP, and $11.8 \%$ of HbA1c. Systemic survey showed acute pyelitis and prostatic abscess. On 
January 19, $2 \mathrm{~g}$ /day of intravenous imipenem was started and an intravitreal injection of ceftazidime and vancomycin was given. On the next day, the density of the vitreous opacity was reduced OS, and cystostomy was performed. Blood culture revealed coagulase negative Staphylococcus sp., which was thought to be the cause of the endophthalmitis. Because bacteremia was found to be absent on January 27, PPL combined with PEA was performed on January 28. A subretinal abscess and the retina above the nasal region were excised and photocoagulation was performed. No bacteria were found in the vitreous samples. Four weeks after the vitrectomy, the BCVA improved to 1.2 OS. The nasal lesion where the subretinal abscess had been resected gradually developed a scar (fig. 2), and the patient underwent secondary IOL implantation OS 5 months later. Clinical findings of the two cases are summarized in table 1.

\section{Discussion}

Ness et al. [8] reported that the visual prognosis depended mainly on the underlying microorganisms, and it was particularly poor in cases of infection with Gram-positive bacteria or Aspergillus sp. There is a trend toward early vitrectomy because of the advancement of vitreous surgery [7, 8]. Yoon et al. [7] reported that a retinal reattachment was found in all cases, and counting finger or better VA was attained in half of the cases after early vitrectomy for endogenous Klebsiella pneumoniae endophthalmitis in 10 eyes. Although a simple comparison cannot be made, our cases attained very good visual outcome despite delayed surgical treatment. One of the reasons may be that the bacteria were less virulent, and another important factor may be that the primary site of the infection was identified and properly treated before bacteremia developed. The primary infection might have been fatal, and eye surgery was a secondary priority. Thus, vitrectomy had to be delayed, but the end result was still very good. This suggests that early vitrectomy is not absolutely necessary in selected cases.

The culture of the vitreous samples did not grow any bacteria probably due to effect of antibiotics. An earlier vitreous biopsy should have been considered because a culture of the vitreous sample is useful for identifying the responsible bacteria. The positive rate is reported to be $87 \%$ for vitreous, $32 \%$ for aqueous humor, and $33 \%$ for blood [8].

Endogenous endophthalmitis is a complex disease and can be caused by a large number of bacterial species. Thus, a specific treatment method for this disease is not available. However, a rapid identification of the causative organism and of the primary infected site must be done. These identifications may be as important as early vitrectomy, and appropriate systemic antibiotic administration may improve the outcome of vitrectomy as in our cases.

\section{Acknowledgements}

Support of this study was provided by Research Grants on Sensory and Communicative Disorders from the Ministry of Health, Labor, and Welfare, Japan and from the Ministry of Education, Culture, Sports, Science and Technology, Japan. No author has a proprietary interest in any material or method mentioned. 
Table 1. Clinical characteristics of the patients

\begin{tabular}{|c|c|c|c|c|}
\hline & \multicolumn{2}{|l|}{ Case 1} & \multicolumn{2}{|l|}{ Case 2} \\
\hline & OD & OS & OD & OS \\
\hline Age/gender & \multicolumn{2}{|l|}{$60 / \mathrm{M}$} & \multicolumn{2}{|l|}{$53 / \mathrm{M}$} \\
\hline Ocular sympton & \multicolumn{2}{|l|}{$\begin{array}{l}\text { pain and blurred } \\
\text { vision }\end{array}$} & & \multirow[t]{2}{*}{ acute visual loss } \\
\hline Bilaterality & \multicolumn{2}{|l|}{ bilateral } & unilateral & \\
\hline Visual acuity at first visit & 0.02 & 0.6 & 1.2 & 0.06 \\
\hline Systemic complications & \multicolumn{2}{|c|}{$24 \mathrm{~kg}$ weight loss during $2 \mathrm{mo}$} & \multicolumn{2}{|c|}{ diabetes mellitus } \\
\hline \multicolumn{5}{|l|}{ Preoperative findings } \\
\hline \multicolumn{5}{|l|}{ Systemic findings } \\
\hline Bacteremia & & \multicolumn{2}{|c|}{+} \\
\hline Focus & \multicolumn{2}{|c|}{$\begin{array}{l}\text { brain abscess, endocarditis, } \\
\text { gingivitis }\end{array}$} & \multicolumn{2}{|c|}{ pyelitis, prostatic abscess } \\
\hline Causative organism & \multicolumn{2}{|c|}{ Streptococcus anginosus } & \multicolumn{2}{|l|}{ Staphylococcus } \\
\hline \multicolumn{5}{|l|}{ Ocular findings } \\
\hline Anterior chamber & $\begin{array}{l}\text { iritis } \\
\text { with fibrin }\end{array}$ & iritis & iritis & $\begin{array}{l}\text { iritis with } \\
\text { hypopion }\end{array}$ \\
\hline Ophthalmoscope & $\begin{array}{l}\text { dense vitreous } \\
\text { opacity }\end{array}$ & $\begin{array}{l}\text { white mass at } \\
\text { fovea }\end{array}$ & $\begin{array}{l}\text { simple diabeic } \\
\text { retinopathy }\end{array}$ & $\begin{array}{l}\text { dense vitreous } \\
\text { opacity }\end{array}$ \\
\hline OCT & N.A. & $\begin{array}{l}\text { mass connected } \\
\text { with ORL }\end{array}$ & normal & N.A. \\
\hline $\begin{array}{c}\text { Bright flash ERG } \\
\end{array}$ & noise level & normal & subnormal & reduced a-wave \\
\hline \multicolumn{5}{|l|}{ Surgery } \\
\hline Period after onset & \multicolumn{2}{|l|}{36 days } & \multicolumn{2}{|l|}{12 days } \\
\hline Intraoperative findings & $\begin{array}{l}\text { subretinal } \\
\text { abscess }\end{array}$ & - & - & $\begin{array}{l}\text { subretinal } \\
\text { abscess }\end{array}$ \\
\hline Visual acuity at final visit & 0.7 & 1.2 & 1.2 & 1.2 \\
\hline Follow-up period (mo) & 10 & & 7 & \\
\hline
\end{tabular}

Mo = months OCT $=$ optical coherence tomography; ERG = electroretinogram; ORL = outer retinal layer. 


\begin{tabular}{l|l|l|l} 
Case Reports in & $\begin{array}{l}\text { Case Rep Ophthalmol 2010;1:56-62 } \\
\text { DOI: 10.1159/000320601 }\end{array}$ & $\begin{array}{l}\text { Published online: } \\
\text { September 21, 2010 }\end{array}$ & $\begin{array}{l}\text { ○ 2010 S. Karger AG, Basel } \\
\text { ISSN 1663-2699 } \\
\text { www.karger.com/cop }\end{array}$ \\
\hline
\end{tabular}
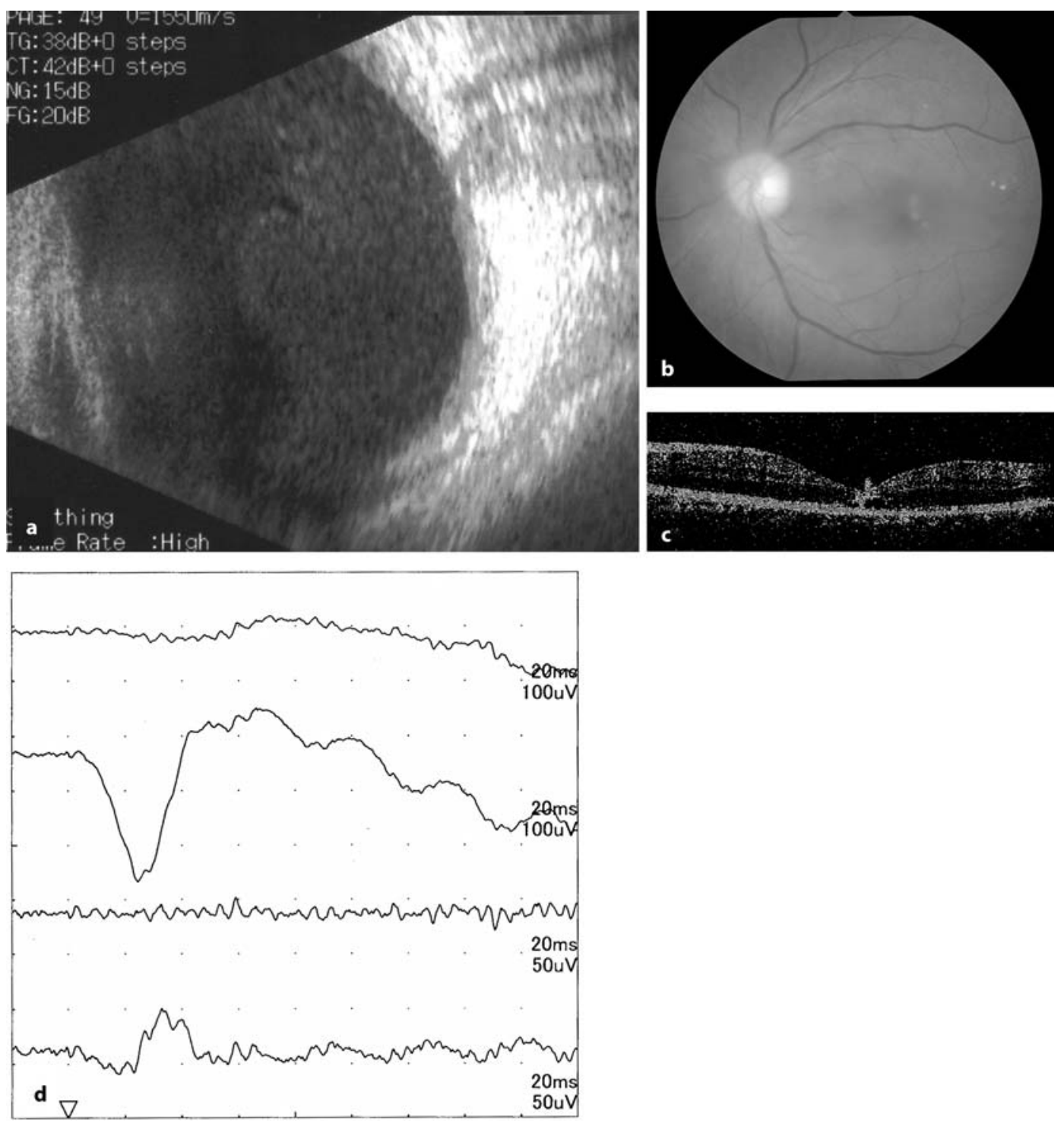

Fig. 1. Ophthalmological findings of case 1 at onset. a US showed no retinal detachment but an aggregated intravitreal mass in the right eye. $\mathbf{b}$ Ophthalmoscopy showed a white mass on the fovea in the left eye. c Optical coherence tomography showed that the white mass shown in $\mathbf{b}$ was continuous with the outer retinal layer. d Single-flash ERG showed almost no response in the right eye and normal responses in the left eye. 


\begin{tabular}{l|l|l|l} 
Case Reports in & $\begin{array}{l}\text { Case Rep Ophthalmol 2010;1:56-62 } \\
\text { DOl: 10.1159/000320601 }\end{array}$ & $\begin{array}{l}\text { Published online: } \\
\text { September 21, 2010 }\end{array}$ & $\begin{array}{l}\text { ○ 2010 S. Karger AG, Basel } \\
\text { ISSN 1663-2699 } \\
\text { www.karger.com/cop }\end{array}$ \\
\hline
\end{tabular}
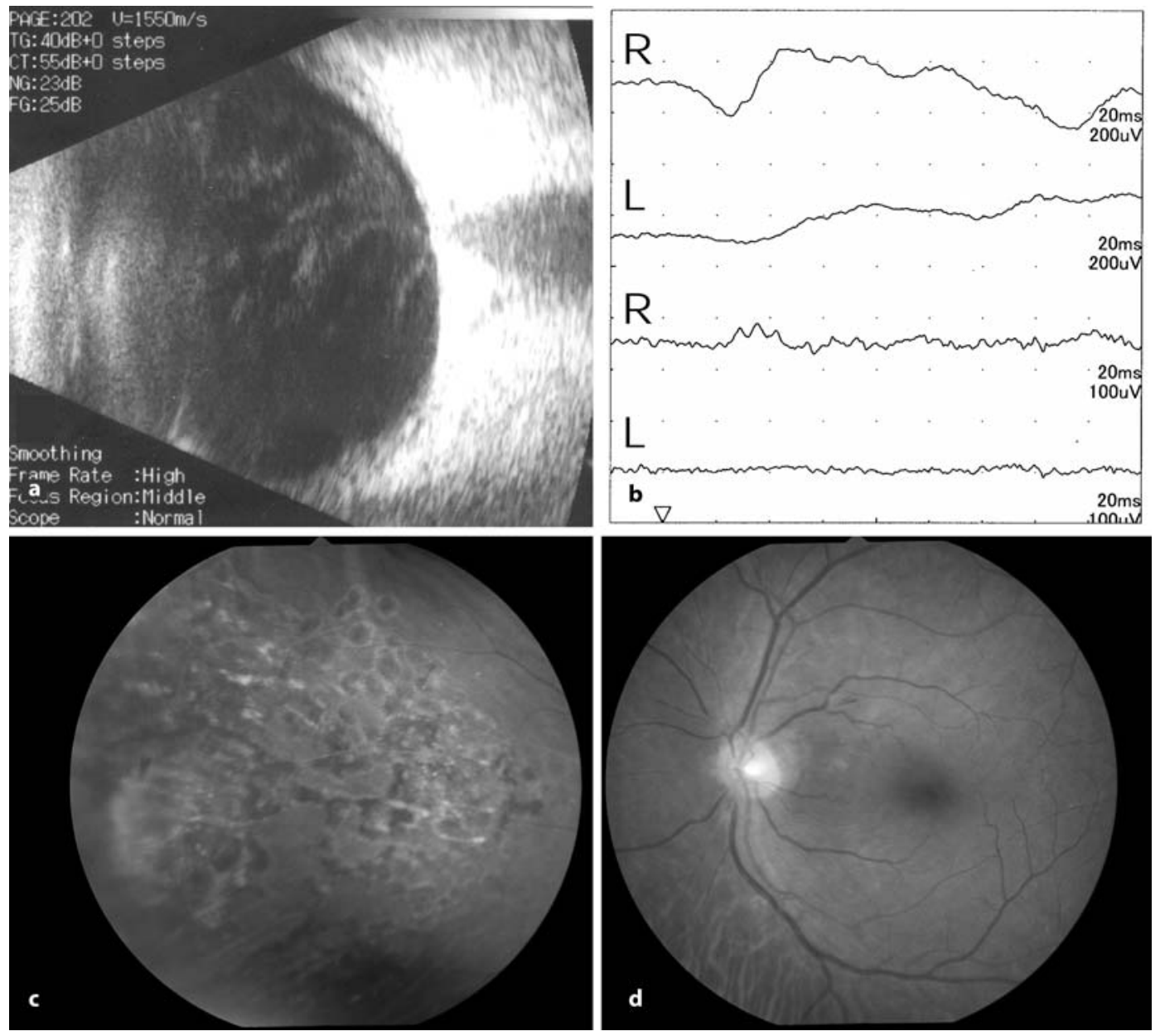

Fig. 2. Ophthalmological findings of case 2. a US showed no retinal detachment but dense vitreal opacity in the left eye. b Single-flash ERG showed severely attenuated a-wave in the left eye. c Fundus photograph of the nasal region in the left eye taken 4 weeks after vitrectomy shows a scar where the subretinal abscess was resected. d Fundus photograph taken 4 weeks after vitrectomy shows no abnormal findings in the left eye.

\section{References}

1 Greenwald MJ, Wohl LG, Sell CH: Metastatic bacterial endophthalmitis: a contemporary reappraisal. Surv Ophthalmol 1986;31:81-101.

-2 Jackson TL, Eykyn SJ, Graham EM, Stanford MR: Endogenous bacterial endophthalmitis: a 17-year prospective series and review of 267 reported cases. Surv Ophthalmol 2003;48:403-423.

3 Hatano $\mathrm{H}$, Inoue K, Matoba $\mathrm{H}$, Kurita $\mathrm{M}$ : Changing trends of bacterial and fungal endophthalmitis. Etiological features [in Japanese]. Rinsho Ganka (Jpn J Clin Ophthalmol) 1989;43:121-124.

4 Okada AA, Johnson RP, Liles WC, D’Amico DJ, Baker AS: Endogenous bacterial endophthalmitis. Report of a ten-year retrospective study. Ophthalmology 1994;101:832-838.

5 Wong JS, Chan TK, Lee HM, Chee SP: Endogenous bacterial endophthalmitis: an east Asian experience and a reappraisal of a severe ocular affliction. Ophthalmology 2000;107:1483-1491.

-6 Harris EW, D’Amico DJ, Bhisitkul R, Priebe GP, Petersen R: Bacterial subretinal abscess: a case report and review of the literature. Am J Ophthalmol 2000;129:778-785. 
7 Yoon YH, Lee SU, Sohn JH Lee SE: Result of early vitrectomy for endogenous Klebsiella pneumoniae endophthalmitis. Retina 2003;23:366-370.

$>8$ Ness T, Pelz K, Hansen LL: Endogenous endophthalmitis: microorganisms, disposition and prognosis. Acta Ophthalmol Scand 2007;85:852-856.

-9 Torii H, Miyata H, Sugisaka E, Ichikawa Y, Shinoda K, Inoue M: Bilateral endophthalmitis in a patient with bacterial meningitis caused by Streptococcus pneumoniae. Ophthalmologica 2008;222:357-359.

10 Yatera M, Ataka S, Ohsugi H, Kohno T, Kubo C, Imamoto K: Early vitrectomy was effective in a case of endogenous endophthalmitis with subretinal abscess [in Japanese]. Rinsho Ganka (Jpn J Clin Ophthalmol) 2006;60:515-518. 